\title{
Influence of Permeability on Axial Symmetric Consolidation Method via Plaxis3D
}

\author{
Binbin $\mathrm{Xu}^{1, \mathrm{a}}$ \\ ${ }^{1}$ Tianjin Port Engineering Institute Ltd. of CCCC, Tianjin, China; Key Lab. of Geotechnical \\ Engineering of Tianjin, Tianjin, China; Key Lab. of Geotechnical Engineering, Ministry of \\ Communication, Tianjin, China; \\ axubinbin@tpei.com.cn
}

Keywords: Plaixs3D AE, axial symmetric consolidation, Terzaghi's theory, Barron's theory.

\begin{abstract}
As an efficient treatment in soft ground, the drainage consolidation methods have been widely used in the engineering. Accordingly, the numerical technical also develops rapidly. The vacuum load is newly added in Plaxis3D AE and the effect of this new feature is discussed in this paper. A simple axial symmetric finite element model with sand well is established to investigate the influence of permeability coefficient on the horizontal consolidation. The results show that as the permeability coefficient of the sand well becomes large, the rate of consolidation also increases. Therefore, the treatment that the drainage line/surface assumes that the drainage capacity of vertical drain is infinite is unreasonable, which may result in overestimation of the ground deformation. The drainage surface is recommended to set on the top of the sand well to simulate the vacuum load and the degree of vacuum can be transferred to the bottom of ground gradually through the sand well.
\end{abstract}

\section{Introduction}

As well known, there is plenty of soft soil widely spread in China. The typical characteristics of the soil are high water content, large compressibility, low permeability and small bearing capacity. If the building is directly constructed on such soft ground, there would be two serious consequences. One is that significant settlement or uneven settlement occurs and will last a long time, which may influence the normal operation or function. Another one is the loss of stability due to the low bearing capacity. Therefore, in order to avoid the damage the reinforcement should be carried out. When the area and the depth of the soft ground are very large, the drainage consolidation method is recommended. The definition of the drainage method is to set additional drainage passage on the soft ground to accelerate the consolidation of ground. Meanwhile, additional load is exerted to generate excess pore water pressure. Along with the dissipation of pore water pressure, the void ratio of soil becomes small and the strength of soil gets larger.

The drainage preloading method includes the drainage system and the loading system. For the drainage system, there are horizontal drainage such as sand cushion and vertical drainage including ordinary sand well, bag-packaged sand well and plastic vertical drains etc. For the loading system, there are surcharge preloading, vacuum preloading, dewatering preloading and electroosmosis preloading. Because of its widely utilization in the practical engineering, plenty of theoretical and numerical achievements have been proposed in the last several decades. Hird et al. [1-2] gave the similar transferring method according to the equal horizontal degree of consolidation. However, Hird didn't consider the smearing effect, horizontal displacement and vertical seepage. Zhao et al. [3] gave the analytical solution of equal strain considering the horizontal displacement and vertical seepage, which is also compared with Barron's solution. When using this method, it is necessary to modify the permeability, while the space of the sand wall can be determined arbitrarily according to the mesh division.

As powerful geotechnical finite element software, Plaxis3D is firstly developed by Delft University of Technology to solve the embankment on soft ground in Holland. After several upgrades, now it is widely used in many kinds of geotechnical engineering such as foundation pit, retaining wall, slope, tunnel, harbor engineering. However, due to the technical limitation the application of 
Plaxis3D in horizontal consolidation doesn't make great progress compared with its application in pit excavation or other geotechnical problems. Recently, the newest version of Plaxis3D adds the function of vacuum preloading. In order to clarify the characteristics of the new function, this paper aims to verify the capacity and feasibility of Plaxis3D in the horizontal consolidation, so that wider application can be used in the future.

\section{Calculation Conditions}

New Features. For the horizontal drainage simulation, there have been drainage line and drainage surface in the program. Namely, on the drainage line/surface the excess pore water pressure is always zero. If there is positive excess pore water pressure caused by surcharge loading, the pore water will flow into the drainage line/surface to represent the consolidation of ground, which is very useful for the surcharge preloading consolidation. However, it is impossible to simulate the vacuum preloading due to the negative excess pore water pressure in the consolidation process. Previously, when using Plaxis3D to deal with the vacuum preloading problems, the equivalent load is simplified to replace the vacuum load. Although the settlement can be predicted to some extent, the horizontal displacement and the pore water pressure deviate greatly between them.

In the new version of Plaxis3D AE, the feature of vacuum is added in the drainage line/surface where the pore water pressure along the drainage line/surface is designated as a negative value so that the pore water can flow into this drainage passage to simulate the vacuum effect. It is a great progress for the horizontal consolidation problems. But there are still some defects for this treatment. Actually, there is obvious well resistance in the sand well and the degree of vacuum will decrease gradually along the depth. The reason lies in that the drainage capacity of the vertical drain is actually finite for the ordinary drainage material which is determined by its permeability but in Plaxis3D AE the drainage capacity of the drainage line/surface is assumed to be infinite. If the actual sand material is assigned to the drainage material and a given negative pore pressure is set inside the sand material, it may solve the simulation of the vacuum preloading consolidation.

Calculation Model. The calculation model is shown in Fig. 1. The model is cubic with same width and length of $5 \mathrm{~m}$ and depth of $2 \mathrm{~m}$. The top surface is free for the nodes in three directions. The rolling restriction condition is applied on the side surfaces and the bottom surface is fixed in three directions. In order to simulate the single axial symmetric drainage, the undrained condition is used for the four side surfaces and bottom surface and the drained condition is applied on the top surface. The mesh density is mediate and there are around 2000 elements. In the middle of the ground, a cube with same depth of the ground and $1 \mathrm{~m}$ width and length is divided in advance to model the sand well.

Soil Parameters. For the ground low permeability and strength soil is used and for the sand well the ordinary sand with large permeability is used. Mohr-Column model is used in the calculation and the soil parameters are listed in Table 1.

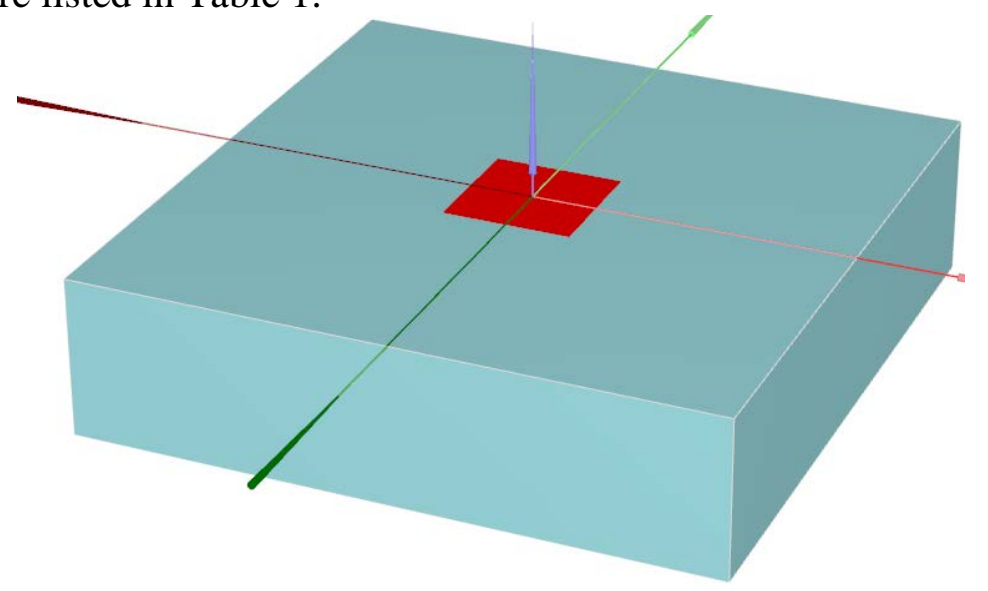

Fig. 1 Finite element model 
Table 1 Soil parameters of ground and sand well

\begin{tabular}{|c|c|c|}
\hline Items & Ground & Sand well \\
\hline Drainage type & Undrained A & Drained \\
\hline Bulk density $\left(\mathrm{kN} / \mathrm{m}^{3}\right)$ & 16.0 & 19.0 \\
\hline Effective Young's modulus $(\mathrm{kPa})$ & 2000 & 10000 \\
\hline Possion ratio & 0.3 & 0.3 \\
\hline Internal friction angle $\left(^{\circ}{ }^{\circ}\right)$ & 3 & 31 \\
\hline Cohensive strength $(\mathrm{kPa})$ & 5 & 1 \\
\hline Permeability $(\mathrm{cm} / \mathrm{s})$ & $1.0 \mathrm{e}-7$ & Depend on case \\
\hline
\end{tabular}

Calculation Schemes. For the vacuum preloading calculation, there are two points that should be noticed. One is that the unsaturated bulk density and saturate density of the soil should be the same, namely there is no suction force caused by the unsaturated soil. Another one is that in the hydraulic condition the soil type should choose user-defined saturated type to make sure that the whole ground is always saturated. In order to investigate the finite permeability of sand well on the consolidation of the ground, the permeability coefficient of the sand well is shown in Table 2.

In order to generate significant excess pore water pressure, a sudden load is added on the top surface of the ground and then is removed quickly. The loading time is so short that the pore water bears nearly all the load. After that, the consolidation process is carried out until the whole degree of consolidation in the ground is over $99 \%$.

Table 2 Permeability coefficient of sand well

\begin{tabular}{|c|c|}
\hline Cases & Permeability $(\mathrm{cm} / \mathrm{s})$ \\
\hline Case 1 & $1.0 \mathrm{e}-7$ \\
\hline Case 2 & $1.0 \mathrm{e}-6$ \\
\hline Case 3 & $2.0 \mathrm{e}-6$ \\
\hline Case 4 & $1.0 \mathrm{e}-5$ \\
\hline
\end{tabular}

Calculation Results. The settlement of ground surface is shown in Fig.2. As can be seen, there are significant differences for the different coefficients of permeability. When the permeability of the sand well is the same as that of ground, which means there is no vertical drainage passage in the ground. For this case, the consolidation obeys the Terzaghi's one dimensional consolidation theory. As the permeability coefficient of the sand well increases, the end point of primary consolidation because earlier and earlier. Here, there are both vertical consolidation and horizontal consolidation, which obeys the Terzaghi's and Barron's consolidation theory. As the permeability of sand well become large enough, the horizontal consolidation become predominate and there will be only Barron's consolidation.

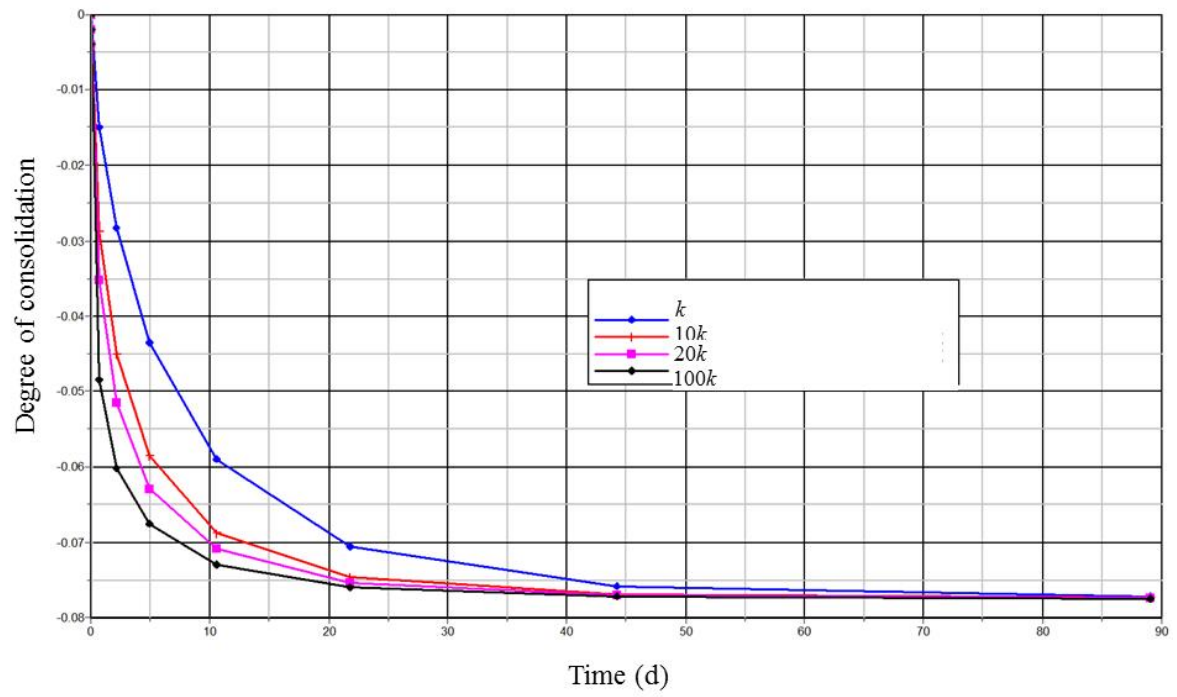

Fig. 2 Relationship between Settlement of top surface and time 


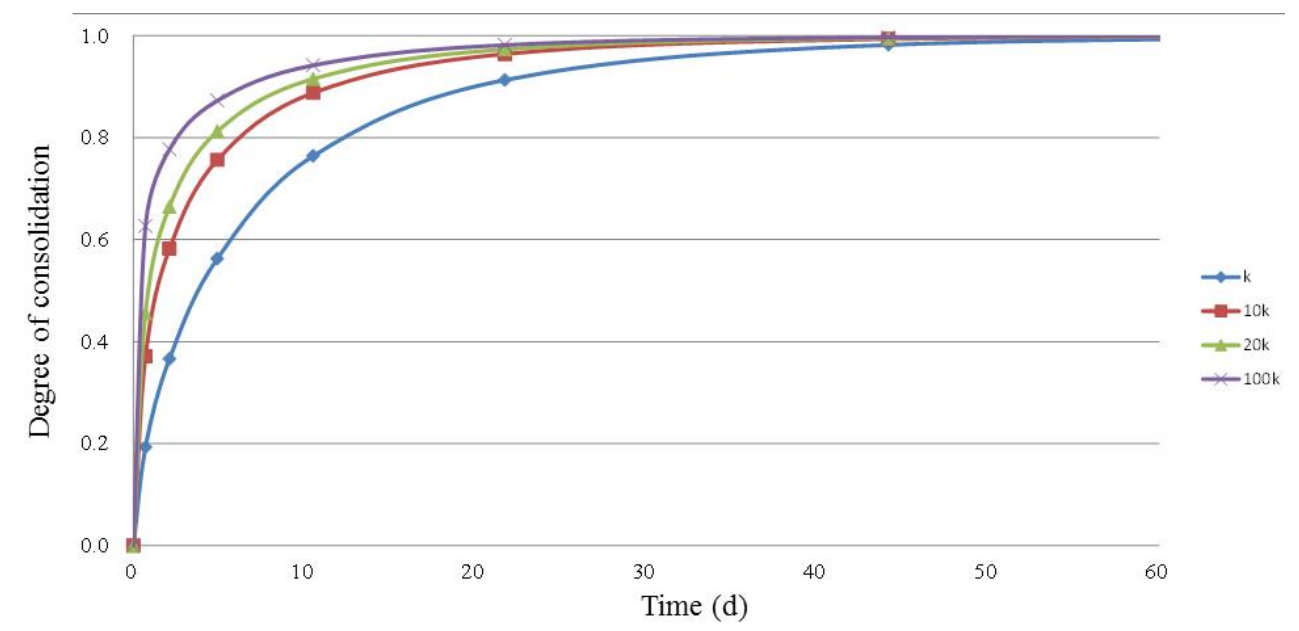

Fig. 3 Influence of permeability of sand well on degree of consolidation in the ground

The variation of consolidation degree in the ground is shown in Fig. 3. Similar tendency can be seen that the larger the permeability of the sand well is, the faster the consolidation is. As mentioned above, although there is no theoretical curves of Terzaghi's and Barron' consolidation the right curve is similar to Terzaghi's curve and the left curve is similar to Barron's Curve.

\section{Discussions}

For the axial symmetric consolidation problems, Plaxis3D AE gives a solution method by assign negative pressure on the drainage line/surface. However, such kinds of treatment believe that the drainage capacity, namely the permeability, is infinite, which is different from the practical condition and may result in the overestimation of the ground deformation. Enlightened by the Barron's theory, a sand well with finite drainage capacity may be used to replace the drainage line/surface. The drainage surface can be set on the top of the sand well to simulate the vacuum load and the degree of vacuum can be transferred to the bottom of ground gradually through the sand well.

\section{Conclusions}

The axial symmetric horizontal consolidation is discussed from both theoretical and numerical aspects and the new feature of Plaxis3D about drainage line/surface is also analyzed in details. The conclusions are as follows:

1) Although the propose of vacuum feature in Plaxis3D AE is a great progress for the vacuum preloading calculation, the drainage capacity of the drainage line/surface is assumed to be infinite, which is different from the actual situation and may overestimate the ground deformation.

2) When there is sand well in the ground, as the permeability coefficient of the sand well becomes large, the rate of consolidation also increases. The consolidation can be assumed varying from Terzaghi’s theory to Barron's theory.

\section{References}

[1] C. C. Hird, I. C. Pyrah and D. Russel, Finite element modeling of vertical drains beneath embankments on soft ground. Geotechnique, 1992(4):499-511.

[2] C. C. Hird, D. Russel and F. Cinicioglu, Modeling the effect of vertical drains in two dimensional finite element analysis of embankments on soft ground. Can. Geotech. J. 1995: 795-807.

[3] WB Zhao, YH Chen, YP Gong, A methodology for modeling sand-drain ground in plain strain analysis, Journal of Hydraulic Engineering, 1998(6):53-57. 